\title{
Trends \& Emerging Areas in Merchant Acquiring Industry
}

\author{
Tapomoy Koley ${ }^{1}$, Shounak Ghosh ${ }^{1} \&$ Shameek Ghosh ${ }^{1}$ \\ ${ }^{1}$ Kolkata, West Bengal, India \\ Correspondence: Tapomoy Koley, Kolkata, West Bengal, India. E-mail: tapomoy99@gmail.com
}

Received: October 20, 2014

Accepted: November 4, 2014

Online Published: December 25, 2014

doi:10.5539/ijef.v7n1p229

URL: http://dx.doi.org/10.5539/ijef.v7n1p229

\begin{abstract}
The Merchant Acquiring Industry landscape is changing at a rapid space. In order to grab a larger market share the acquirers are coming up with new innovative products and remodelling the old products. Along with their attempts of creation of a niche market segment by help of product differentiation they are also desperately trying to penetrate into unexplored \& underpenetrated market segments and adopt new unconventional ways for revenue generation. The paper does a comprehensive study to trace the trends \& emerging areas of opportunity across the industry. It also tries to explore underpenetrated and unpenetrated market segments.
\end{abstract}

Keywords: merchant acquiring, fraud prevention, analytics, merchant financing, ecommerce, mcommerce, digital wallet, loyalty

\section{Who is a Merchant Acquirer?}

Acquirer is an institution that provides the necessary infrastructure (e.g. Point of Sale /POS devices) to the merchants so that they can accept and process payment card transactions. Merchants send out their processed credit card transaction details to the acquirers and acquirers in turn pay out to the merchant. On the other hand acquirers transmit those transaction details to the card issuing organizations and receive money from them. However both transfer of data and transfer of funds between acquirer and issuer take place via credit card payment schemes (like Visa, MasterCard, Chinese Union Pay). Payment Schemes play an important role in credit card processing life cycle as they lay down the processing rule \& regulations and also facilitate transaction processing. Card issuing organizations (can be banks like Bank of America, Chase or financial institutions like Amex, Discover) ultimately recover the money from the card holder. Across the globe there are many players who offer acquiring services to the merchants. Apart from financial institutions (like First Data, Vantiv, Heartland Payment Systems, WorldPay) who have specialized in acquiring business, very often we see banks (like Bank of Chase, Wells Fargo, Barclays, Sberbank) offering acquiring services to the merchants.

\section{Present Industry Structure}

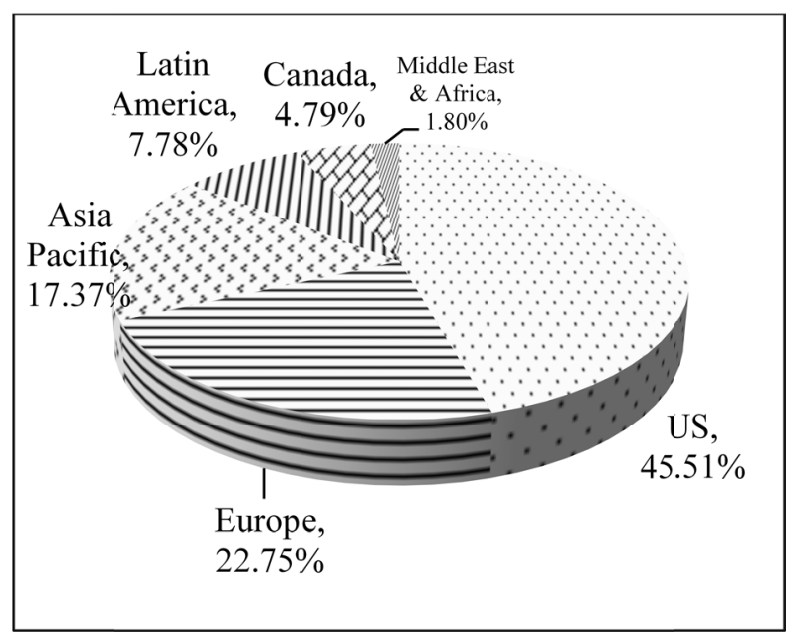

Figure 1. Purchase transaction count 2012 global market share 
Analysis of 2012 worldwide purchase transaction count suggests US and Europe are the two top geographies for Merchant Acquiring Industry. With 114 Billion transaction count, their combined global market share is around $68 \%$. As part of this research we have mainly focussed on the acquiring industry of US and Europe which in turn covers major part of the global card industry.

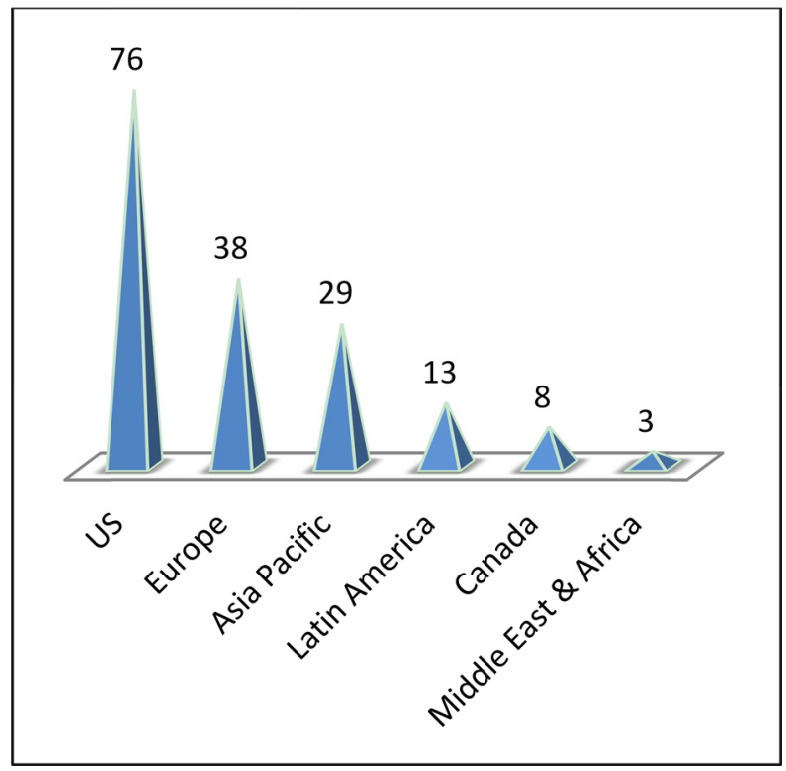

Figure 2. 2012 Worlwide purchase transaction (By transaction count in Billion)

*Source: Nilson Report.

The merchant acquiring market typically displays Oligopoly characteristics. However the industry landscape appears to vary rapidly as we move from one part of the world to the other. In US and Europe we see different acquirers acting as industry leaders. According to Nilson Report only two acquirers - Elavon and WorldPay, feature in the top 10 Acquirer list of both US and Europe. As part of this study special attention has been given on the product range and strategic moves of the top 10 players of both geographies.

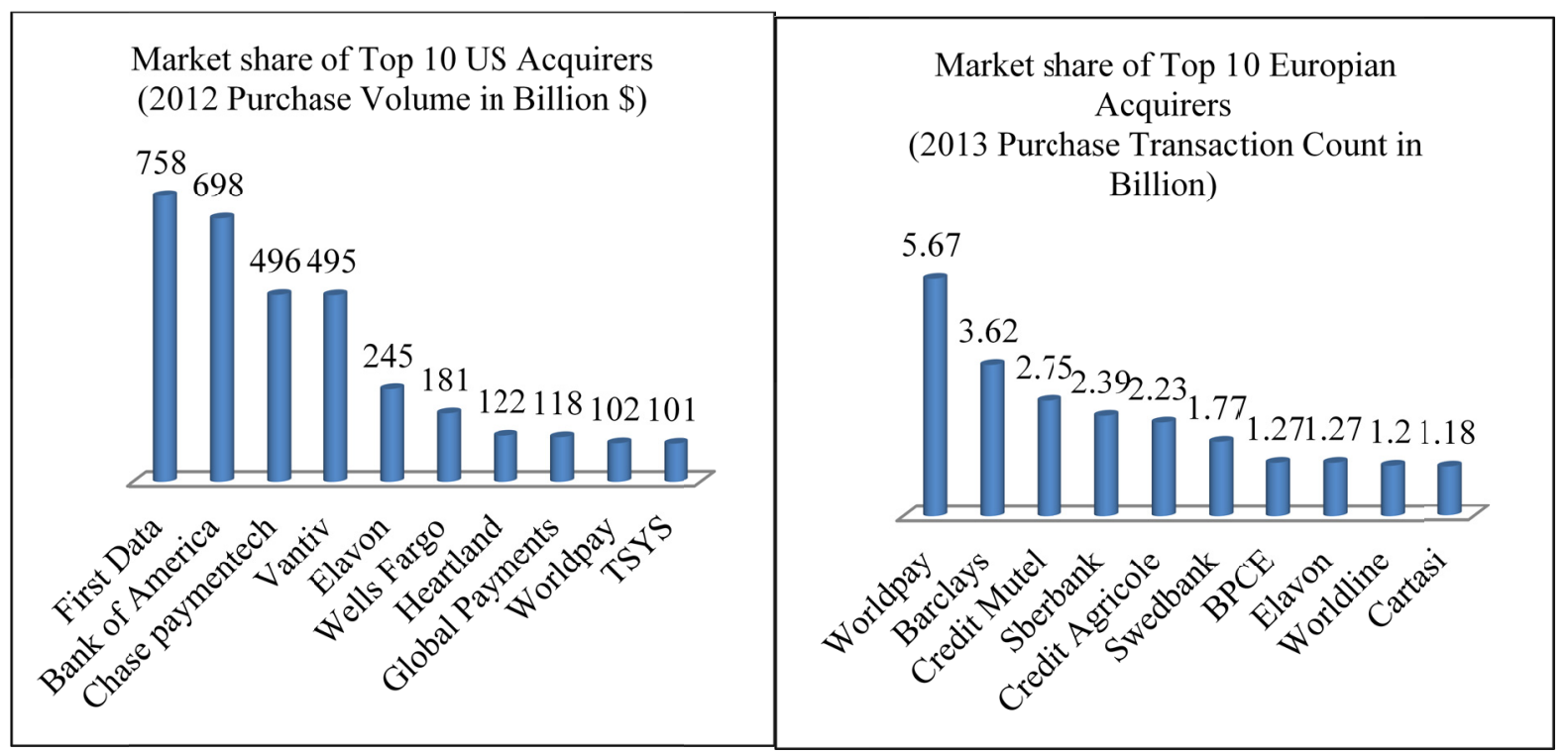

Figure 3. Market share of different acquirers

*Source: Nilson Report. 


\section{Trends \& Emerging Areas}

Acquiring Industry is changing at a rapid pace. The acquirers are trying to transform themselves from "A traditional payment processor" to "A trusted business partners" of the merchants. The prevailing intense competition, pursuit of new revenue stream, aspiration to project themselves as business partners and adoption of new technologies for business growth are driving the trends \& emerging areas of Merchant Acquiring Industry.

\subsection{Fraud Prevention Measures}

Preventing fraud would continue to remain as a key area of focus for acquirers. Despite measures taken in past years, the cost of payment card fraud reached \$11.27 Billion in 2012 (up 14.6\% over 2011) which translated to a loss of 5.22 per $\$ 100$ transaction volume (source: Nilson Report). Major data breaches like Kmart and Home Depot (2014), Target and Adobe (2013), Global Payments (2012) etc. re-emphasized the need for robust fraud prevention mechanism to be in place for both ATM \& POS transactions and CNP transactions.

EMV, Tokenization, Point to Point Encryption, One time password, Single use card number are some of the leading fraud prevention technologies currently available in the market. Aite Group survey at MasterCard's Global Risk Management Conference (May, 2014) hints at greater acceptability of EMV, Tokenization and End-to-end encryption technologies compared to others. In fact for combating ATM \& POS frauds EMV has already emerged as a success story in Europe. According to 2014 European Central Bank report (based on Eurosystem regions) ATM and POS frauds declined in absolute term over the full period from 2008 to 2012 owing to high EMV adoption. In $51 \%$ cases POS \& ATM frauds were committed using counterfeit cards however those were mainly committed outside SEPA where EMV adoption is yet to gain momentum. According to Nilson report, U.S. is the only region where counterfeit card fraud continues to grow consistently. As of now US card issuers bear the losses when counterfeit cards are used at POS \& ATM. However the liability would shift to retailers after Oct, 2015 if they have not upgraded their hardware by then. The Payments Security Task Force (formed in March 2014) has been working towards enhancing payment system security across US and right now the organization is keenly pushing all players to become EMV compliant by Oct, 2015. Undoubtedly upgrading all their processing platforms to make them EMV compliant and making their merchant base EMV compliant would remain a priority area for acquirers.
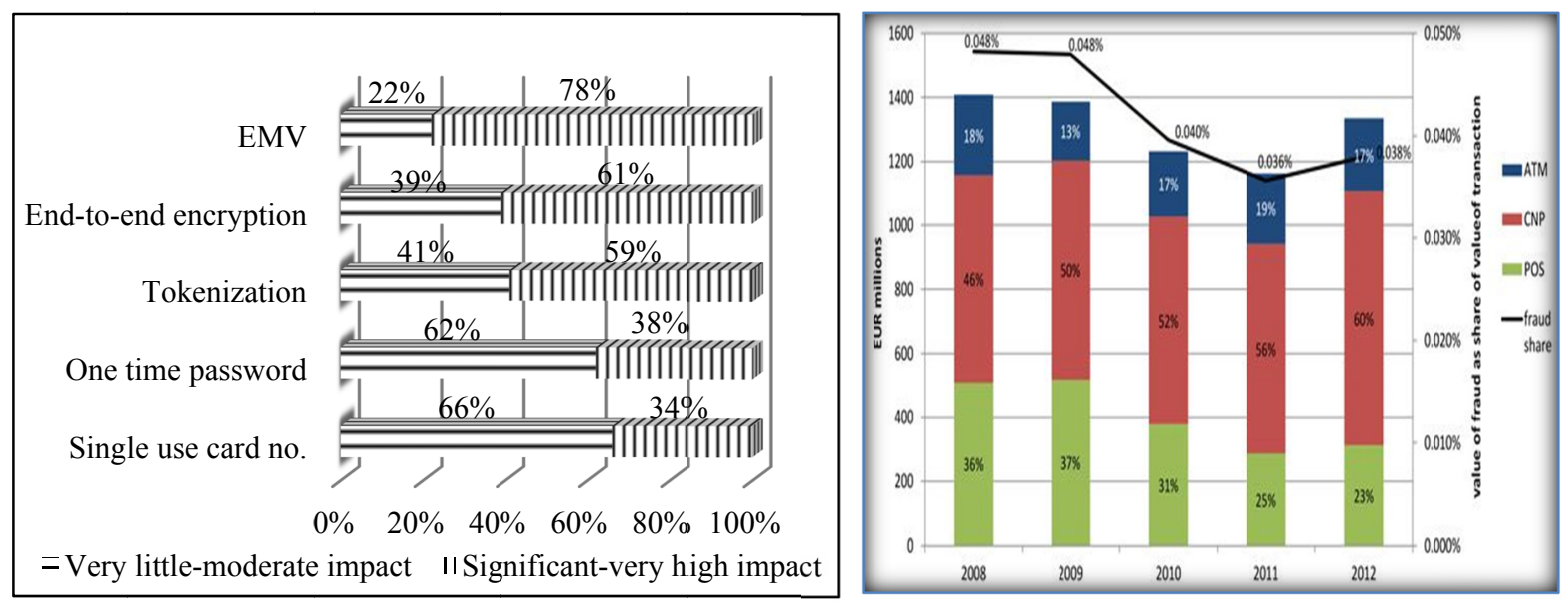

Figure 4. Effectiveness of various fraud prevention technologies

*Source: Aite group survey and 2014 European Central Bank report.

Increasing EMV adoption across the globe has forced fraudsters to migrate towards CNP transactions. According to 2014 European Central Bank report (based on Eurosystem regions) in 2012 CNP fraud accounted for $60 \%$ of total fraud loss. According to Nilson report (August 2013) merchants and acquirer losses mainly occur on CNP transactions (on the web, at a call centre or through mail order) since liability of such transactions is with acquirers or merchants. Previous attempts to secure internet transactions with the help of additional secret numbers (such as CVV2 or 3D secure code) achieved only some initial, limited success. Tokenization and Point-to-Point Encryption (P2PE) have emerged as an advanced 360 degree solution in protecting CNP transactions. Most of the leading acquirers do offer such advanced products like Transarmor (First Data), Safetech Fraud \& Security Solutions (Chase), Vault \& PayPage and Vantiv Secure (Vantiv), SAFE-T (Elavon) 
etc. Currently Visa, MasterCard and Amex are introducing a common tokenization and encryption solution and acquirers across US are upgrading their systems to offer this new solution to their merchant base. On a whole industry wide application of the existing solution and/or devising newer fraud prevention techniques is all set to continue as a major action point for acquirers.

\subsection{Analytics}

Unlocking the potential trapped in Big Data and use of Analytics to arrive at a business decision is all set to become a 'must have capability' for merchants. Day by day more and more merchants are taking the help of analytics to drive growth and engage customers. Many bigger merchants have been using this for quite some time. It already has a prominent presence among ecommerce segment both in US \& Europe in form of products like Adobe SiteCatalyst, IBM Coremetrics, Google Analytics, Webtrends and Snoobi. Right now it is slowly moving into brick \& mortar SMB space at an affordable price. Analytics solutions are available both from acquirers and other organizations. However acquirers appear to have edge over others as they have larger POS terminal data available with them. There are a variety of analytics products that are currently available in the industry, each one has its unique feature and different analytical capability. Some products are powerful enough to predict sales volume/ inventory requirement based on weather forecast/ other factors, locate customer base, analyse in-store customer behaviour to recommend preferable store layout, break customers into specific segments and give valuable recommendation for engaging customers like launching offers targeting specific customer segment. While some simpler products could only offer features like providing trend reports. Easy online accessibility of the analytics data through mobile app is a much sought after feature for the business owners. Also the SMB owners would prefer to have a one stop solution where they can view the details and also act upon the recommendations (like launching offer etc.). In fact scope of analytics is increasing on a regular basis and now it is been used for fraud protection as well. A recent Wall Street Journal highlights Visa's new predictive analytics service that is helping fight fraud at gas stations. A pilot test of predictive analytics software from Visa helped reduce fraud at Chevron gas pumps by $23 \%$ over a two month period.

According to 2011 Mckinsey report, organizations that use Big Data and analytics effectively show productivity rates and profitability that are 5-6\% higher than those of their peers. McKinsey analysis of more than 250 engagements over five years has revealed that companies that put data at the centre of the marketing \& sales decisions improve their marketing return on investment (MROI) by $15-20 \%$ which adds up to $\$ 150-\$ 200$ billion of additional value based on global annual marketing spend (estimated to be $\$ 1$ trillion). For US Retail sector the figures are even more encouraging - more than 60\% increase in net margin and 50-100\% annual productivity growth. In US some of the top 10 acquirers who offer analytics products are First Data (Spend Trend), Vantiv (Business Insights), TSYS (Merchant Insights). On June 2014, First Data launched 'Insightics' which appears to be a pretty smart analytics solution for SMB merchants.

\subsection{Business Diversification}

The trend to diversify the business and offer services/ products which are not typically an acquirer's job is slowly gaining momentum. Owing to the long association with the merchants these businesses have good success potential. There are three different businesses - Merchant Financing, Consumer Lending and Online Food Ordering \& Delivery Facility - where the acquirers are specifically taking interest right now. In future we may expect more players to enter into those areas or venture into other unexplored areas like Shipment Facility, Legal Consultation Facility etc.

\subsubsection{Merchant Financing}

Due to strict criteria of getting bank loans (owing to 2008 recession and Dodd-Frank Bill), it has become difficult for SMB segment to get finance to cover their operational cost or growth requirements. Merchant Financing helps a merchant with not so good credit score to get short term financing from an acquirer (or a financial lender who has tied up with the acquirer). There are four formats of offering Merchant Financing: Traditional Loan, Merchant Cash Advance, Business Overdrafts \& Credit Cards and Borrowing against Assets. Out of these four alternatives, acquirers who are not typically wearing the additional hat of being a 'Bank', have been involved in offering the first two to their merchants on account of merchant's past sale volume.

Traditional Loan: In this format, the merchant repays the principal \& interest within fixed tenure.

Merchant Cash Advance: In this format the lender would provide lump sum fund to business in exchange for a fixed contracted amount of future receivable and would deduct a percentage of the business' daily payment card income till the time contracted amount is recovered. This is essentially a 'Future Contract' and not a 'Loan'. Therefore no interest is levied but the difference between the lump sum received from lender and the fixed 
contracted amount of future receivable, makes the profit for lender. The repayment tenure is variable and gives a merchant the much desired flexibility of paying less when sale volume is less. However, though there is uncertainty in payback tenure but leveraging their long association with the merchant and access to past business history the lender's profit amount differs to take care of the expected payback tenure. The product generally has very high effective APR (Annual Percentage Rate) but as it is outside the ambit of loan regulations, it does not create any legal problem for lender. Other features of this business includes fast cash access, less documentation and dealing with high risk merchants (who may not get loans from banks).

The estimated short term lending to SMB sector presents around \$2BN profit opportunity in US and merchant cash advance market is around $\$ 500-\$ 700 \mathrm{MN}$, with the potential to reach $\$ 3-\$ 5 \mathrm{BN}$ within the next several years in US (source: 2013 Oliver Wyman study and 2013 Green Sheet estimates). It can also help an acquirer to penetrate into SMB segment which is a fiercely fought region for acquirers. As per McKinsey report, in 2011 the acquirer revenue from $\mathrm{SMB}$ sector was $\$ 10 \mathrm{BN}$ in comparison to $\$ 1.4 \mathrm{BN}$ for large players in US. Amex $\left(2^{\text {nd }}\right.$ largest credit card payment scheme in US) offers traditional loan through Amex Merchant Financing since 2011. On Nov, 2013 Heartland Payment System became the first acquirer to distribute Amex Merchant Financing product. Merchant Cash Advance is offered by Square (launched Square Capital on May, 2014 \& announced its expansion following an agreement with Victory Park Capital on Aug, 2014) and PayPal (launched PayPal Working Capital on Sep, 2013). 4 out of top 10 US acquirers - First Data, Vantiv, WorldPay and TSYS offer Merchant Cash Advance Services in collaboration with some of the leading cash advance providers in the industry. Barclay, BPCE, First Data, PayPal are some of the players who offer Merchant Financing in UK.

\subsubsection{Consumer Lending}

Revolving credit attracts very high interest rate for a cardholder [average credit card APR in US is $13.02 \%$ as of Sep $25^{\text {th }} 2014$ (source - http://www.bankrate.com/finance/credit-cards/rate-roundup.aspx)]. But consumer lending provides an alternate, cheaper option to cardholders. Acquirers can offer this using their own capital or capital of a lender. This form of lending can be extended in two ways - Deferred Payment (allows cardholder to make a payment after some days) and Instalment Payment (allows cardholder to pay in fixed no. of EMIs). Out of these two products Instalment Payment appears to be much better option for a cardholder as it helps in superior financial planning and avoid debt trap. A quick glance at revolving credit data of Federal Reserve suggests that there is huge scope for this kind of product.

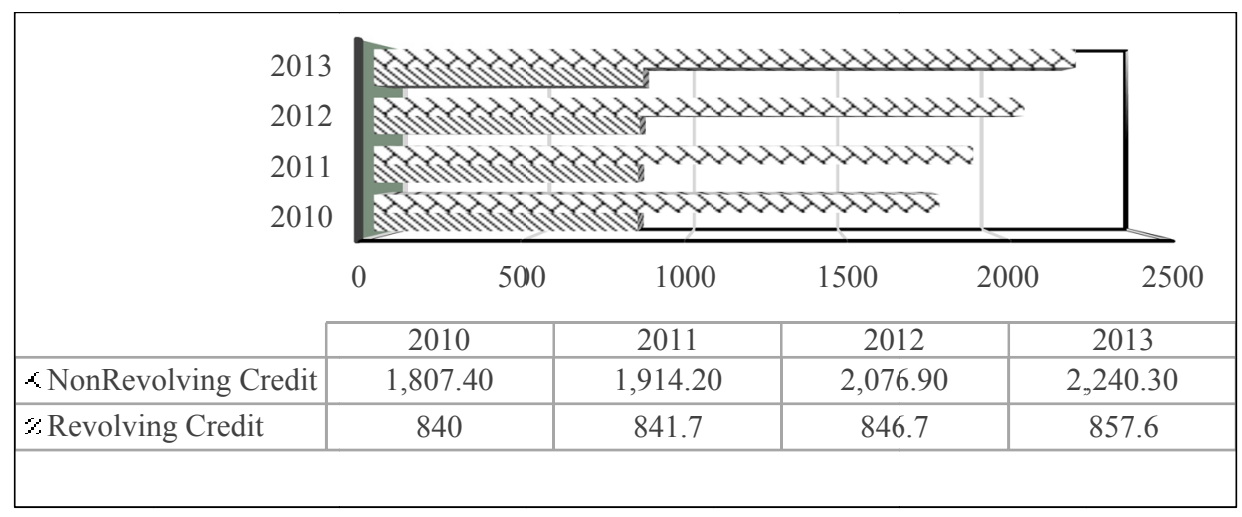

Figure 5. Total outstanding credit in US, 2010-2013 (in Billion \$)

*Source: Federal Reserve, US.

Deferred Payment is offered by products like Bill Me Later (line of credit offered by Comenity Capital Bank), Pay Later by Affirm. Instalment Payment is offered by Split Pay (launched on July 10, 2014 by Affirm for ecommerce). The merchants would receive its payment upfront while cardholder would pay Affirm the total amount due (principal \& interest) in fixed no. of EMI. Cardholders would be charged a percentage (say $6 \%$ or more) of the amount while the merchants would be levied a processing fee (2-3\% of the amount). However Affirm is currently signing up merchants directly and is yet to tie up with any acquirer.

\subsubsection{Online Food Ordering \& Delivery Facility}

Restaurant SMB merchants find it difficult to increase their revenue by accommodating more customers inside restaurant owing to capital constraint. Online Food Ordering \& Delivery Facility hellps the owners to earn 
additional revenue without big infrastructure investment. It allows cardholders to place restaurant order via an acquirer maintained website/ mobile app to any of the participating restaurants. The acquirer may also provide home delivery service on behalf of restaurants. Data from National Restaurant Association suggest fair scope for this kind of offering. As per their estimate there will be $\$ 683.4 \mathrm{BN}$ sales in SMB intensive restaurant industry (around 990,000 restaurants) in 2014, working out to 47\% share of all food dollars in US. A survey conducted by them hints at growing popularity of using smartphone/ tablet for order takeout / delivery. In US PayPal started 'Order Ahead' in 2013 and in UK it started on March 2014. Square launched 'Square Ordler' on May 2013 in US and acquired Food Delivery Service Provider Company 'Caviar' on August 2013.

\subsection{Innovative POS}

With radical changes in the payment industry one of the prime area of focus becomes the innovation of the Point of Sale device. Primarily defined as a device that can accept credit/debit card payments, this device has moved far away from its basic functionalities of only facilitating payments. Today this device acts a one-stop solution for multiple business needs. The innovative POS terminals allow merchants to accept payments via multiple methods \& connectivity channels, provide high security, cater to loyalty and analyse the processed data to generate trends \& recommendations. The POS solutions varies from industry to industry customized on the industry needs, like a POS specialized for restaurant has the capacity to enter the tip amount for individual transaction before hitting for settlement, while that of retail has the facility to have detailed line items of the purchase.

The prime modification came in with the functionality to process chip and PIN transactions confirming with EMV specifications. This is considered as the most important feature in POS by the Payments Cards and Mobile Survey 2014. Another innovation came in with the acceptance of various alternative forms of payment like contactless cards etc.

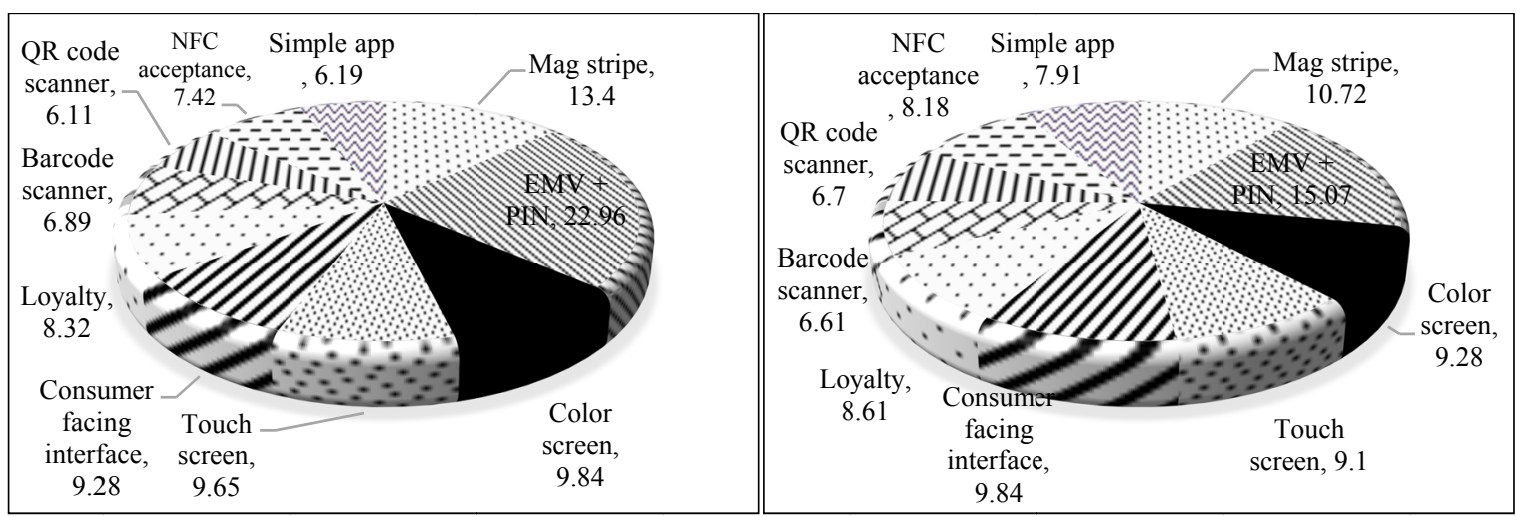

Figure 6. Main Features of current POS

Figure 7. Features required in an innovative POS

Source: 'Innovation at POS Survey 2014' by Payments Cards and Mobile.

Merchant loyalty has recently emerged as a big area of focus. POS devices of new age are well equipped for handling loyalty based programs. With newer innovations the POS device is providing additional features like real time analytics and marketing needs like offer generation and redemption.

The new generation POS devices has gone far more by merging with a smartphone or tablet to act as a payment method with addition of a software application and a card reader. With more sophistication came more emphasis on security that enabled the devices to carry out various transactions securely. The tablet/computer POS along with Cloud connectivity has redefined the payment industry with most of the leading market players investing hugely in this kind of POS, be it the Shopkeep POS of TSYS, Clover of First Data or Mobile checkout by Vantiv. Apart from the Tablet based POS, smartphone based POS has become very popular due to its sheer simplicity in processing transactions. Square, the market leader of SMB sector started square reader which uses the $3.5 \mathrm{~mm}$ headphone jack to connect to a smartphone and integrate with the app to process payments securely via internet. Similar products like Intuit's Go payment, IPay POS, Merchant ware mobile, First Data"s POGO etc. came into the market. With the advent of e-commerce \& m-commerce proving to be market drivers, the innovation in payment acceptance through Payment Gateway (which plays the role of Point of Sale device for online transactions) has come in the industry. 


\subsection{E-Commerce \& M-Commerce}

Electronic Commerce or E-commerce as it is well known, dates back to 1979 when the first online shopping process connecting a domestic TV to a real-time transaction processing computer via phone line. With the advent of World Wide Web or the internet the e-commerce industry of today started its baby stepis. Currently $39 \%$ of the world population is internet user with a growth rate of 676\% from 2000 to 2014 (source: Internet World Stats). With such meteoric rise in internet usage the electronic commerce industry is also growing substantially. In US market the growth of Retail E-commerce market is phenomenal.

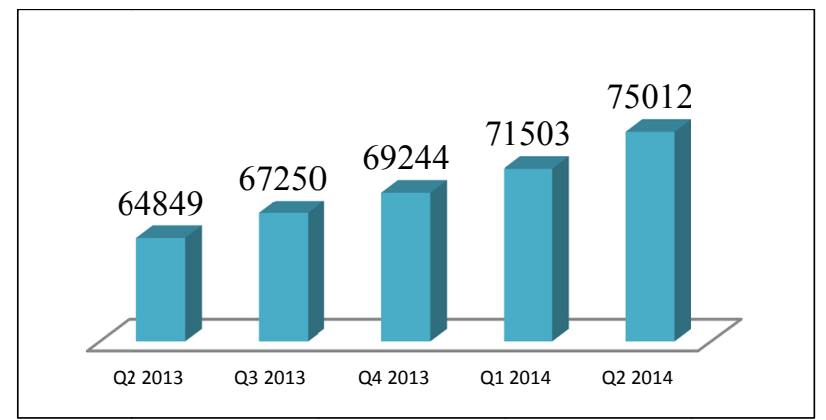

Figure 8. Estimated US ecommerce retail volume (in \$ Mn)

*Source: US Gov. Census, Ecommerce report, Aug 2014.

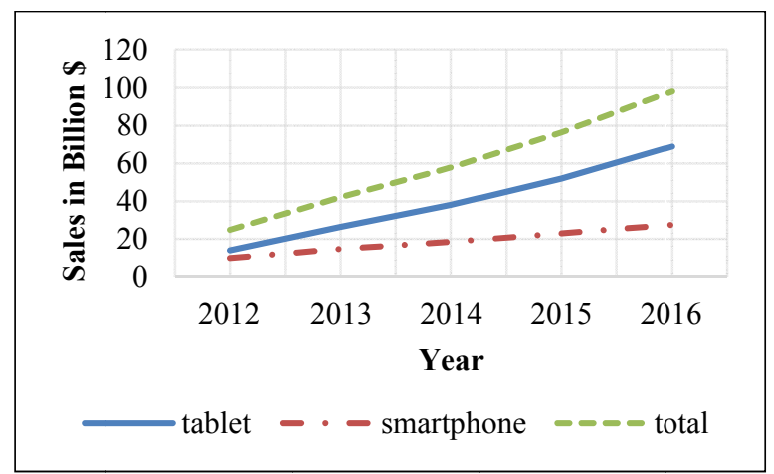

Figure 9. M-commerce sale in retail - US

*Source: eMarketer, April 2014.

However E-commerce growth is not only confined in US, it is indeed a global phenomenon. According to Emarketer, in the year 2012 the global B2C ecommerce sales touched \$1 trillion. APAC region in specific is expected to witness a boom in E-commerce industry.

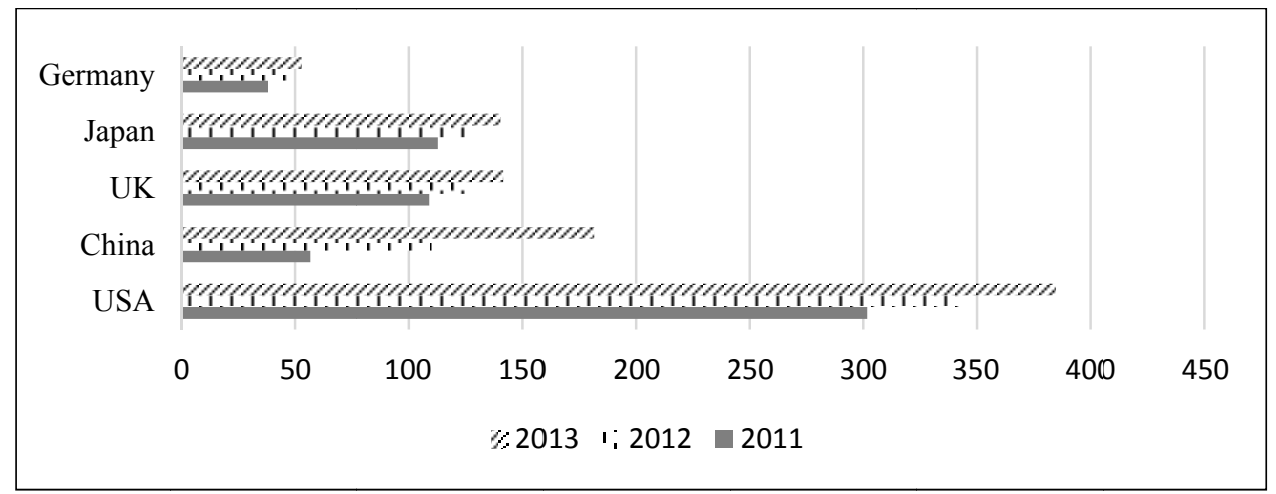

Figure 10. Top 5 countires by B2C e-commerce sales (in Billion \$)

*Source: Emarketer, Jan 2013. 
E-commerce merchants can be categorized into 3 broad categories-

- Pure-click or pure-play: Those who have launched a website without any previous existence as a firm

- Bricks-and-clicks: Existing companies that have added an online site for e-commerce

- Click-to-brick: Online retailers that later open physical stores to supplement their online efforts

More and more merchants are now moving from a brick \& mortar model to an online model in order to reduce infrastructure cost and changes in customer spending pattern. To cater to this need of conversion acquirers have come up with products that provide a complete e-commerce solution to a merchant from brick to click. Acquirers provide a solution to create an online store with integrated payment acceptance capacity like Payeezy ecommerce solution from First Data, Square Market from Square.

Mobile Commerce or simply M-commerce refers to purchase or sales of goods or services with the use of handheld or mobile devices like Smart phones or Tablets. In the current age of consumer adoption of web-enabled mobile devices and mobile marketing, the volume percentage of M-commerce is increasing. Forrester.com estimates that $29 \%$ of all online retail sales in the US will be transacted on smartphones and tablets by the end of 2014 with total sales hitting an all-time high of $\$ 114$ Billion in 2014. In recent days many e-commerce merchants have a mobile app which enables mpos payments. Acquirers have also added service of integrating the mobile payment services for e-commerce websites.

In recent times, a lot of stress is given on the security of e-commerce transactions since they are considered to be more vulnerable to fraud. Security mechanisms like encryption, tokenization have been introduced in most of the e-commerce products. Payment schemes like Visa, MasterCard and Amex have recently announced their tokenization product for ecommerce merchants. In the current E-commerce and M-commerce space it is not just the traditional retail players, other industries (like - restaurant, transport, fleet, car-rental) are also venturing with new ideas and products. The online food ordering or transport ticket booking or car booking is gaining immense popularity.

\subsection{Supporting Alternate form of Payment}

As the saying goes 'change is the only constant', payment industry also follows that. When cash, cheque were the normal method of payment, cards came in as the alternate payment method. Now that the cards have become a common payment method, various other methods have come in the scenario.

With the up gradation of technology the payment mechanism changed from swiped/inserted (in case of EMV) to a contactless device with the usage technologies like NFC (Near Field Communication) and Bluetooth. The process allows acceptance of payments without physical contact of the card.

Another alternate payment instrument is Digital wallet, where a software is used to store the card information in a secured manner. Since it can hold multiple card information, hence the name wallet is given. It also stores shipping information. Users can pay in e-commerce as well brick and mortar using the wallet. Digital wallet or e-wallets are very popular in China - contributing to around $44 \%$ of e-commerce transactions (source: World pay report 2014 - Your global guide to alternate payments - second edition). PayPal, an online wallet, has become very popular in e-commerce space. Google launched its flagship product Google Wallet in 2011 with huge expectation, however, as per many experts it has not lived up to it. The reason as stated by Jonathan Wall, founding engineer of Google Wallet was the lack of carriers. Success of a wallet depends on the partners like network providers, merchants, which for Google Wallet was pretty less having MasterCard and Sprint as partners. Square withdrew Square Wallet on May, 2014 which was unveiled in 2011. Recently apple launched Apple Pay along with its flagship mobile device Iphone6. Apple has not only tied up with payment schemes, it has enlisted major retail brands along with its own i-tunes to give the wallet a start from day one. Apple has also launched a new product 'ibeacon' leveraging the Bluetooth Low Energy (BLE) technology which allows a beacon enabled smartphone device to track products and offers for a seamless checkout. More recently some wallets have upgraded to make it hassle free by using single touch payments like PayPal one-touch, where users would need only one touch to complete a transaction. Another new method of payment by wallet was introduced by atpay, which allows users to pay via emails after signing up with the service. Users would click the @pay link to get the complete order summary, and reply with confirmation to that email to process the order.

Bitcoin started in the year 2009 as software based payment system and gradually started being used as a method for e-commerce payments. User can get bitcoin by selling something against bitcoin or buying them from exchange with bank. Merchants can accept and get paid in currency or bitcoin as per their choices. It is currently being accepted by some big companies like DELL, ZYNGA etc. BitPay - the largest bitcoin processor provides services to more than 40,000 businesses. It has processed more than $\$ 100 \mathrm{Mn}$ in 2013 and has hit a million dollar 
sales per day in 2014. PayPal is currently upgrading their system to integrate with 3 major bit coin processors including BitPay.

Another new method of payment is by QR code or bar-code. QR code is more efficient than bar code having data in horizontal and vertical. For a transaction, the seller can generate a QR code with the item details and amount via mobile app and the buyer scans the same and selects the account/card from its mobile wallet to pay. As per Nielsen report, around $74 \%$ of smartphone owners who pay via smartphone prefer using QR code or bar code, while the corresponding figure for tablet owners is around $61 \%$. Despite security concerns apparently this is becoming a very popular payment method for smartphone and tablet users.

In the world of alternate payments Host card emulator is a new entrant, which is a presentation of a virtual card/exact representation of smart card thru software installed in the OS. The contactless transaction is done using NFC technology. This was first published by SimplyTapp. Inc. in 2012. This method gained popularity with its inclusion in Android OS 4.4 and Visa, MasterCard supporting this payment form in Mobile World Congress 2014. This mechanism is currently used in Chicago transit cards (Ventra).

\section{7 Loyalty}

Loyalty or discount offers has been age-old technique for retailers to attract new customers, promote new products and services and encourage repeat visits. Statistics shows that repeat customers typically spend $67 \%$ more than new ones (source: 'SMBs Shift Priority to Customer Retention', Joint Report by BIA/Kelsey and Manta). According to Gartner $80 \%$ of company's revenue comes from $20 \%$ of existing customers.

With time, distribution of offers has become predominant through SMS, Social media \& online offer publishers such as Microsoft's Bing Offers Card-Linked, CardSpring etc. This has brought welcome boost for card-linked marketing programs. In order to simplify offer redemption process, companies like Cardlytics, Edo, Linkable Networks etc. provide card-linked offers solution for participating banks. Traditional payment processors have also come up with similar solutions as value-added services to their merchants - for e.g. First Data OfferWise, Vantiv Prewards, Global Payments tie-up with Edo etc.

Card-linked offers have been around for several years, but as technology and mobile capabilities surrounding them advance, industry players are pulling together to create international standards to streamline growth and development. The CardLinx Association, formed in October 2013 with Bank of America Merrill Lynch, Discover, MasterCard, American Express, PayPal, First Data Corp., Microsoft, Facebook and LivingSocial, set up shop to establish increased interoperability, eliminate friction and promote the growth of the card-linked offers industry.

Mobile based Loyalty solution can become a key differentiator for the payment processors. First Data has been one of the early movers this space by acquiring Perka - A mobile based loyalty platform which helps connecting retailers with consumers through their mobile phones.

Statistics shows more than 50\% of merchants cannot identify their most loyal customers (source: 'Making Every Interaction Count: How Customer Intelligence Drives Customer Loyalty', whitepaper by Acxiom and Loyalty 360). There is a scope of payment processors to enter into this white space and help merchants with analytics \& tools to recognize loyal customers and boost up their sell through generating appropriate loyalty program.

\subsection{Growing Focus on APAC}

According to Nilson report Asia Pacific region is expected to grow by $145 \%$ and occupy the 2nd spot (only next to US) in purchase transaction share by 2018. In APAC still most of the transactions are being done in cash and payment industry in the region is presently undergoing massive transformation. As per MasterCard's study conducted in 2013, China (the biggest APAC economy \& $2^{\text {nd }}$ largest in world) is still in "Transitioning" phase in its journey towards cashless environment while in India (the $3^{\text {rd }}$ largest APAC economy \& 10th largest in world) it is still in "Inception" phase. Financial Inclusion initiatives by the respective governments and fast growth of domestic card schemes (Chinese Union Pay \& Indian RuPay) are responsible for current massive payment industry transformation in those 2 large economies. Undoubtedly APAC is attracting attention of the global acquiring industry leaders and is expected to do so in coming years as well. To gain quicker access to the market, acquirers are either entering into strategic alliances with local players to gain quicker access to the market or taking the route of Merger \& Acquisition. For e.g. First Data's tie up with Standard Chartered, Bank West and ICICI, Acquisition of Ezidebit by Global Payment etc. 


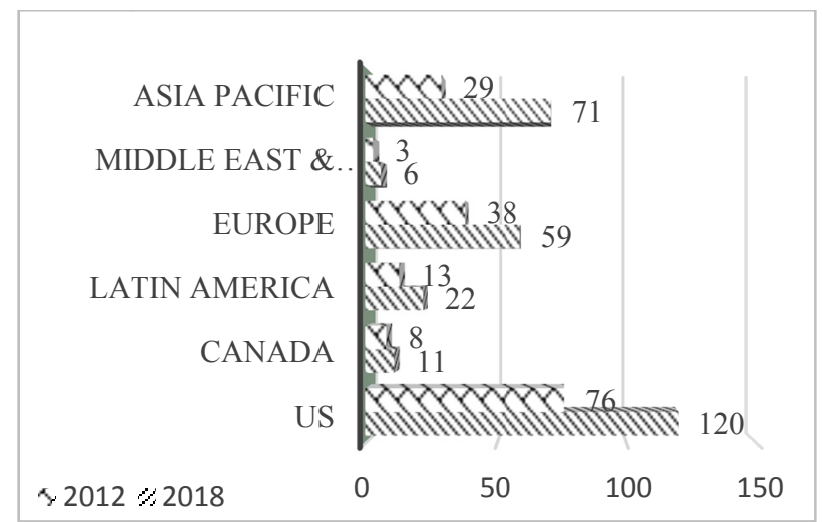

Figure 11. Projected growth in global purchase transaction count (BN)

*Source: Nilson Report.

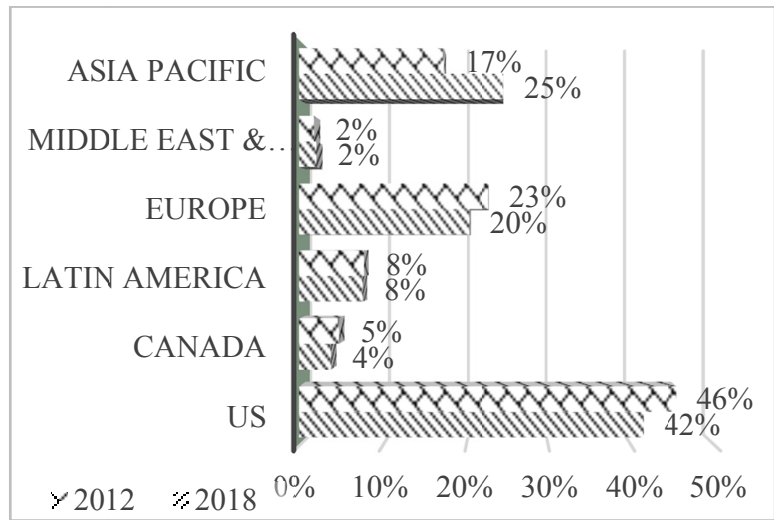

Figure 12. Projected growth in global purchase transaction share

*Source: Nilson Report.

\section{The Road Ahead}

Merchant Acquiring industry leaders across the globe appear to be investing a lot of money to acquire new capabilities to increase the potential value addition they can offer to the merchants. From being just an ordinary processor they are re-inventing themselves as business catalysts and they are most likely to continue on the same track in the coming years. They are making good investment in IT for product development. At the same time they are trying to make their processing smart \& efficient where ever applicable and save money in the process. An extremely interesting trend is being observed for some of the acquirers who are even selling their in house solutions as products to other firms. For e.g. Apple launched iphone6 (Sep, 2014) which has a digital wallet facility named 'Apple Pay' and First Data is providing tokenization service for both POS and ecommerce transactions for the wallet.

Apart from building in-house capability they are taking the route of inorganic growth through Merger \& Acquisition of start-ups and other firms to increase their product range. For e.g. Acquisition of Clover by First Data (on 2012) which helped it to launch innovative POS terminal for SMB merchants, Acquisition of Mercury Payment Systems by Vantiv (on 2014) helped it to offer integrated payment technology to merchants. Acquirers are also entering into strategic partnership with other firms to increase their product offerings. For e.g. TSYS partnered with Womply (San Francisco based start-up) to launch TSYS Merchant Insights (on Nov 2013) which is an analytics solution for the merchants.

The merchant acquiring industry has to adapt with the fast changes in payments landscape -

- Shifting competitive landscape - new players like PayPal \& Alibaba (latest addition) are going to provide tough competition to the traditional payment processors 
- $\quad$ Emerging payment paradigms - Non-traditional payment options gaining traction; e.g., Contactless in-store payment over phone, Frictionless payments over social media, Bluetooth LE /Beacons, Apple Pay ${ }^{\mathrm{TM}}$, PayPal, Virtual currencies, Host card emulation etc.

- Changing customer expectation - With proliferation of smart devices and emergence of Omni Commerce, customers expect personalized \& consistent experience across all channels. Payment processors will have to continuously invent newer means to live up to customer expectations

\section{References}

Anonymous. (2012). B2C eCommerce Sales Top \$1 Trillion. Retrieved from http://www.kineticgrowth.com/b2c-ecommerce-sales-top-1-trillion-in-2012/

Anonymous. (2012). Five Customer Retention Tips for Entrepreneurs. Retrieved from http://www.forbes.com/sites/alexlawrence/2012/11/01/five-customer-retention-tips-for-entrepreneurs/

Anonymous. (2013). The Global Journey From Cash to Cashless. Whitepaper from MasterCard.

Anonymous. (2013). US Mobile Phone And Tablet Commerce Forecast. To 2018 by Forrester Research.

Anonymous. (2014). Dell Begins Accepting Bitcoin. Retrieved from http://dealbook.nytimes.com/2014/07/18/dell-begins-accepting-bitcoin/?_php=true\&_type=blogs\&_r=0

Anonymous. (2014). How Visa's Predictive Analytics Fight Gas Pump Fraud. Retrieved from http://blogs.wsj.com/cio/2014/08/07/how-visas-predictive-analytics-fight-gas-pump-fraud/

Anonymous. (2014). Sacramento Kings Fans Can Now Buy Tickets And Merchandise With Bitcoin Via BitPay. Retrieved from http:/techcrunch.com/2014/01/16/sacramento-kings-fans-can-now-buy-tickets-and-merchandise-with-bitco in-via-a-new-bitpay-partnership/

Anonymous. (2014). The Modern Wallet: Mobile Payments are Making Life Easier. Retrieved from http:/www.nielsen.com/us/en/insights/news/2014/whats-in-your-wallet-mobile-payments-are-making-life-e asier.html

Anonymous. (2014). Visa Launches Innovative Token Service. Retrieved from http://www.businesswire.com/news/home/20140909006526/en/Visa-Launches-Innovative-Token-Service\#. VDsCb7CUeSo

Anonymous. (n.d.). Host card emulation. Retrieved from http://en.wikipedia.org/wiki/Host_card_emulation

Anonymous. (n.d.). Making Every Interaction Count: How Customer Intelligence Drives Customer Loyalty' whitepaper by Acxiom and Loyalty 360 .

Anonymous. (n.d.). Sizing up Merchant Cash Advance. Retrieved from http://www.greensheet.com/emagazine.php?story_id=542

Anonymous. (n.d.). SMBs Shift Priority to Customer Retention. Joint Report by BIA/Kelsey and Manta.

Anonymous. (n.d.). Why Apple Pay Might Succeed With Mobile Payments Where Google Wallet Failed. Retrived from http://marketingland.com/google-failed-can-apple-succeed-apple-pay-99406

Beyond Credit Scores. (n.d.). Affirm Launches Deferred And Installment Credit for Online Sales. Retrieved from http://www.digitaltransactions.net/news/story/Beyond-Credit-Scores_-Affirm-Launches-Deferred-And-Inst allment-Credit-for-Online-SalesBitpay, retrieved from https://bitpay.com/

E-commerce. (n.d.). Retrieved from http://en.wikipedia.org/wiki/E-commerce

European Central Bank. (2014). Third Report on Card Fraud.

Federal Reserve Statistical Release. (2014).

GDP ranking. (n.d.). Retrieved from http://data.worldbank.org/data-catalog/GDP-ranking-table

Getting Started with Bitcoin. (n.d.). Retrieved from https:/bitcoin.org/en/getting-started

Google. (n.d.). Google Wallet Creators Reflect On Its Failures, Lessons. Retrieved from http://www.fastcompany.com/3021913/reverse-engineered/google-wallet-creators-reflect-on-its-failures-les sons

Innovation at POS Survey. (2014). Payments Cards and Mobile sponsored by First Data.

Internet Usage Statistics. (n.d.). Retrieved from http://www.internetworldstats.com/stats.htm 
McKinsey Report. (2011). Big data: The next frontier for innovation, competition, and productivity.

McKinsey Report. (2013). Driving merchant services and digital commerce: Findings from McKinsey’s 2012 U.S. Small Business Acquiring Panel.

$\begin{array}{lllll}\text { Mobile } & \text { Commerce } & \text { Trends. } & \text { (n.d.). } & \text { Retrieved }\end{array}$ http://www.emarketer.com/Webinar/Mobile-Commerce-Trends/4000088

$\begin{array}{llllll}\text { National Credit } & \text { Card } & \text { Rates. } & \text { (n.d.). } & \text { Retrieved }\end{array}$ http://www.bankrate.com/finance/credit-cards/rate-roundup.aspx

Oliver Wyman Study. (2013). Financing Small Businesses: How 'New-Form Lending' Will Reshape Banks Small Business Strategies.

Online Shopping. (n.d.). Retrieved from http://en.wikipedia.org/wiki/Online_shopping

Payment Cards. (n.d.). Current Threats and Protections. Retrieved from http://aitegroup.com/report/payment-cards-current-threats-and-protections

QR Pay. (n.d.). Retrieved from http://www.qrpay.com/

Restaurant Industry Forecast. (2014). National Restaurant Association.

US Gov. Census. (2014). Ecommerce report.

Visa Token Service. (n.d.). Finally a unifying platform for mobile and digital payments. Retrieved from $\mathrm{http} / / /$ usa.visa.com/clients-partners/technology-and-innovation/visa-digital-solutions/visa-token-service/ind ex.jsp

World Pay Report. (2014). Your global guide to alternate payments (2nd ed.).

\section{Copyrights}

Copyright for this article is retained by the author(s), with first publication rights granted to the journal.

This is an open-access article distributed under the terms and conditions of the Creative Commons Attribution license (http://creativecommons.org/licenses/by/3.0/). 